\title{
The Effect of Perspiring on Conductivity in Electronic Textile Design
}

\author{
Mehmet Zahit BİLİR ${ }^{1}$, Mustafa Oğuz GÖK ${ }^{1}$ \\ ${ }^{1}$ Department of Textile and Fashion Design, University of K.Maraş Sütçü Imam, Kahramanmaraş, Turkey
}

\begin{abstract}
It has been seen great advances in technology in recent years. One of these advances has become in smart textile. Although there are many different definitions, usually smart textiles can be defined "sense and respond to environmental stimuli". They have been different application areas such as e-textiles, nano textiles, technical textiles, etc. In the last decades, e-textiles developments come to the fore in the smart textiles. E-textiles contain some digital, electronical circuits, sensors and textile based materials such as conductive fiber, yarn and fabrics. A lot of products can be made in this industry but the effects of environmental stimulis such as human perspiring on these products are not examined so much. In this study, it was examined the conductivity of e-textile fabrics in the changing different $\mathrm{pH}$ values according to gender. Acidic and alkaline solutions have been applied on conductive fabrics and results have been examined with SEM and resistance measure. As a result of the study, it is found that perspiration doesn't affect the conductivity on conductive textile surface badly. In contrast, conductivity has the better result when perspiration solution used. Conductivity increased for each pattern and $\mathrm{pH}$ solutions because of decreasing resistance.
\end{abstract}

Keywords: E-textile, smart textile, intelligent textile, conductivity

\section{INTRODUCTION}

One of the changing and advancing fields of smart textiles is named as e-textiles. The first e-textile application was made in 1850 with the aim of electro-therapy $[1,2]$, so the historical development of e-textiles started. The following applications have gained momentum with the developments in technologies. The first wearable computer was made in 1955 by Edward Thorpe to beat the dealers by using some electronical devices on clothings (Figure 1).

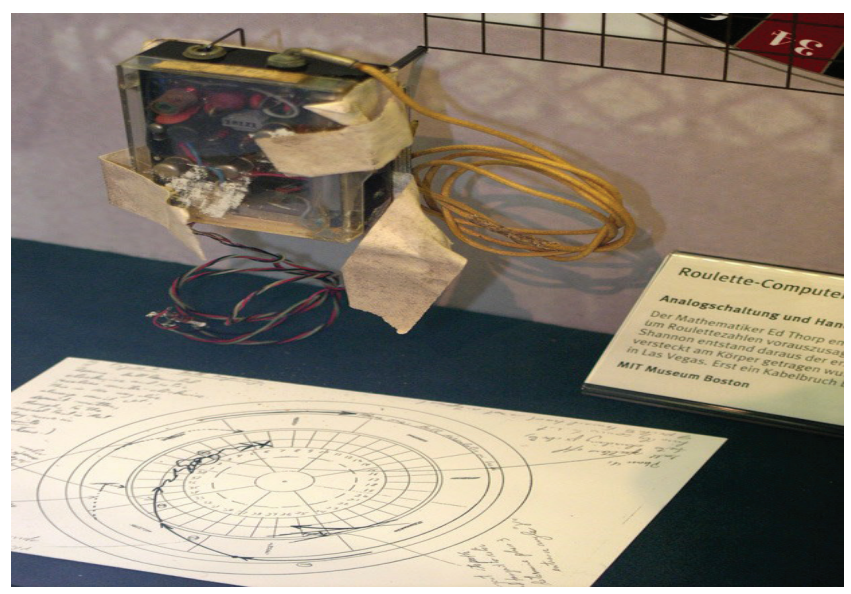

Figure 1. Wearable computer system of Thorpe [3]
In 1966, smart t-shirt developed by Georgia Tech Board Design and Developer to watch the vital signs of soldiers and navy [4]. The more professional and interesting productions have started to be seen in last decades as the combination of textile and electronic. This new e-textile area is named as textronic and many materials have been used together with computer software programs [5]. Astronauts, fire men, polices, patients etc. wear these e-textile clothings in their special areas. Since wearing of e-textile clothings have increased, quality expectations of these produces increase parallelly. Battery life, durability, small sizing, flexibility, lightness, conductivity, portability and etc. have been classified in terms of quality expectation. Conductivity is the one of the most important quality expectation in wearable textiles because these systems work with electricity. Continuous conductivity provides continuous electric current. Conductivity have been affected by many factors and one of these factors is perspiring. In this study, affects of perspiring have been examined with different conductive fabrics and $\mathrm{pH}$ solutions. Results show us that perspiring has no negative affect on conductive fabrics and in contrast, it increases the conductivity rates positively. 


\section{CONDUCTIVITY AND PERSPIRATION}

Conductivity changes from a lot of variables such as environment temperature, resistance of conductive yarns, user-source stimulus such as perspiration. The first description of the perspiration "Moisture caused by escaping fluid in the extremities of blood vessels" is made by Aristotle. Definitions that related sweat glands were made in the 1600s, but it has not seen widespread acceptance until the 1800s. The importance of that began to understand at the 20th century. The human body has a sensitive structure. It can make various chemical reactions together [8]. This reaction is carried out at constant temperature. Body temperature is kept constant in different ways. Shrinkage of blood vessels and shaking are mechanisms that preventing reduction in body temperature. The most important mechanism to prevent increased body temperature is perspiration. First command for sweat production comes from the brain. A significant amount of water and salt are lost with perspiration from the body. Besides urea, uric acid and certain toxic substances are excreted together with sweat [6].

Sweat glands are found mostly in the upper body such as at the palms, soles, front part of the head, shoulder and neck. It is very important to sweat in order to protect the normal body temperature of 36.5 degrees. This value is measured under the seat and it varies in different parts of the body. For example, the measured temperature is around 37 to 37.5 degrees from the mouth or anus. Body temperature is higher in children than in adults. At the time of ovulation, women body temperature indicates an increase of at least 0.5 degrees. Even between the morning and evening, body temperature differences. The lowest temperature at $6 \mathrm{o}$ 'clock in the morning and the highest temperature occurs in the afternoon [6].

Human perspiration is defined as a saline fluid secreted from sweat glands in the AATCC 15-1979. Sweat is a liquid consisting of water, salt (mainly $\mathrm{NaCl}$ ), urea, uric acid, amino acids, ammonia, sugars, lactic acid and ascorbic acid. Human perspiration mechanism can be seen at the Figure 2.

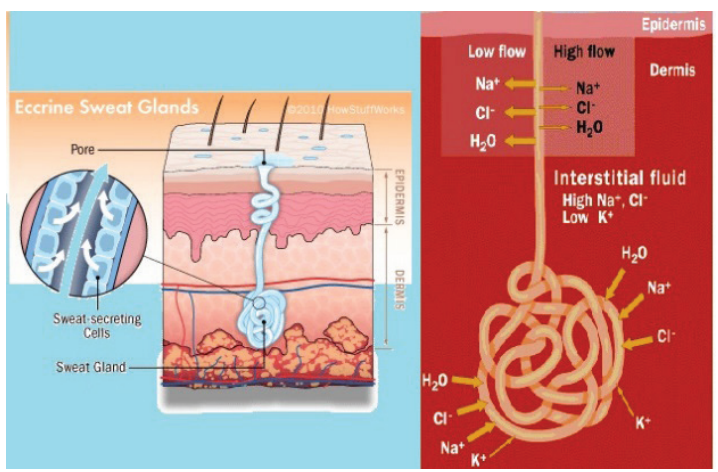

Figure 2. Human perspiration mechanism [7]
The sweat of human firstly has an acidic structure when out of the body. But the result of bacterial activity, it occurs alkaline structure with the increased amount of ammonia. Thus, perspiration fastnesses are made at the $\mathrm{pH}$ (5.5 and 8) $[8,9]$. A liquid must be separated to ions for transmitting of conductivity. $\mathrm{Na}+$ ions are pulled by cathode and they are neutralized by electron. $\mathrm{Cl}$ - ions are pulled by the anode and located on the more electron are left and it becomes neutral. The electrons released to the anode returns again to cathode on wire. Thus, electrical current is provided. Pure water does not transmit electricity, but saltwater transmit electricity. Gases not conduct electricity under normal conditions but if the favorable conditions are created, they can transmit. If the gases are ionized by any means, they may become conductive. In this case, $(+)$ ions will go to the cathode and (-) ions will go to the anode. The current will pass from circuit. Requirements for transmitting electric of the gas are high voltage and low pressure. It must provide the ability to ionized for transmitting electric of the gas.

\section{ELECTRONIC TEXTILE APPLICATIONS}

Nowadays, many different kinds of e-textiles are available in alot of areas such as medical, technical, fashion and etc. the others. Guo and his friends made a wearable e-textile production to detect breathing rhythm in human in 2013 [10]. They have used piezoresistive sensors so system could detect change in the body with change of resistance in sensors when the user breathed (Figure 3).

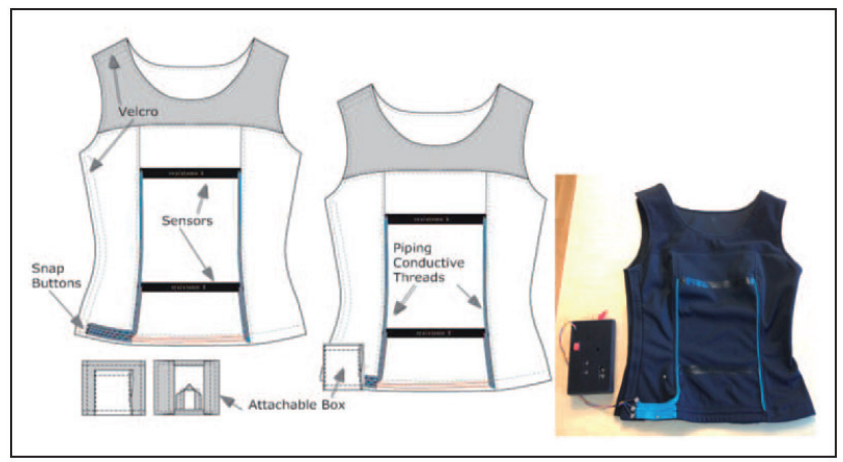

Figure 3. Medical e-textile application

The other application made by Curone and friends in technical textile area is named as smart garments for emergency operators (Figure 4). In this project, portable sensors and devices used for emergency operators to keep far away from dangerous conditions. The clothing system detected heart rate, breathing rate, body temperature, blood oxygen saturation, position, activity, and posture and environmental 
variables such as external temperature, presence of toxic gases, and heat flux passing through the garments) and these data processed [11].

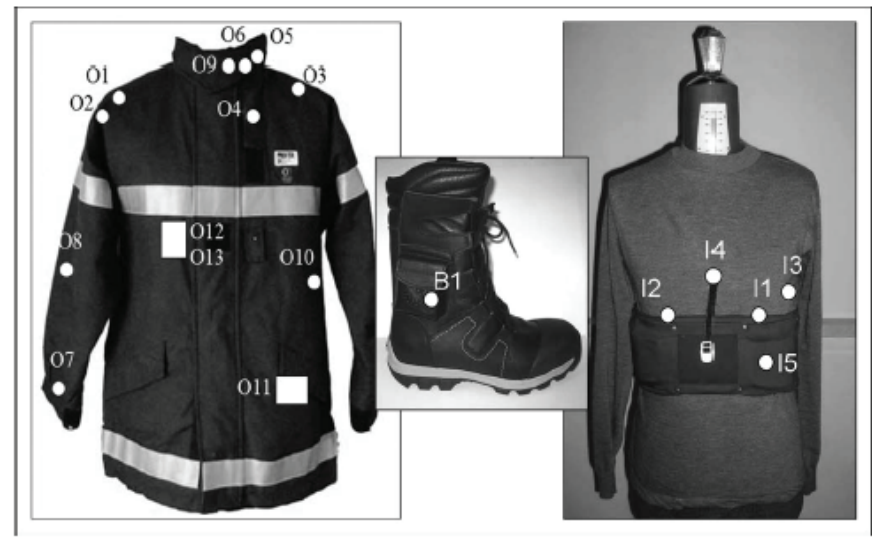

Figure 4. Smart garments for emergency operators

Not only does e-textile productions use in technical areas but they are also used in fashion area. Nowadays, fashion designer have been interested in LED integrated clothing surfaces, so they can manage to make different designs apart from conventional textile clothings (Figure 5).

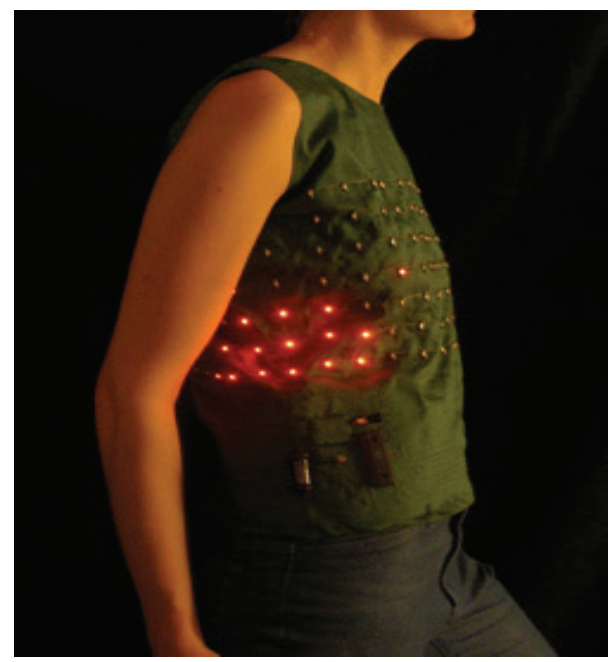

Figure 5. LED integrated clothing [12]

Main materials of e-textiles are conductive yarns capable of conducting electric from parts of units. Conductive yarns can be made by using conductive fibers or several coating materials. Although there are a lot of different methods in conductive yarn production, wrapping and coating production methods are mostly more in the industry (Figure 6). It is expected from an e-textile production that it must be washable, non-allergic and comfortable on human skin [13], so metal conductive yarns aren't used so much because of their too fragile and heavy structures.

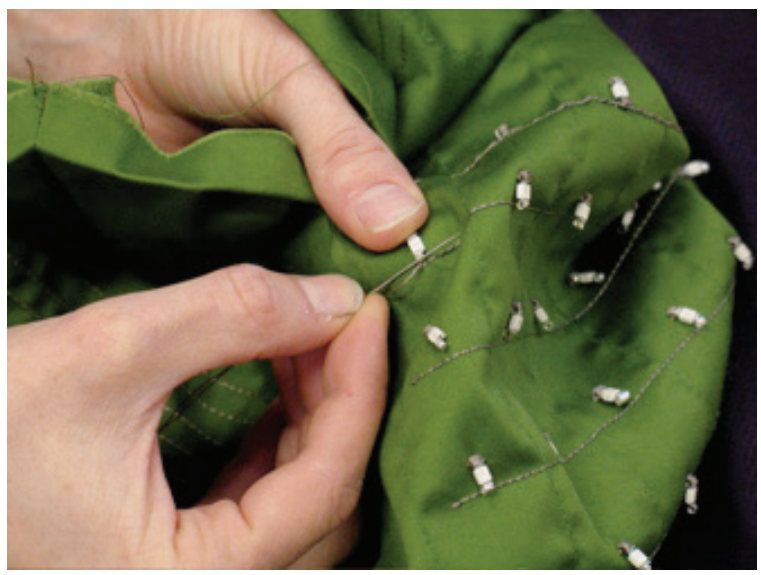

Figure 6. Conductive yarn with LEDs [14]

In the production of conductive fabric stracture, conductive fibers and conductive yarns are used. Weaving or knitting of these materials are applied with the same production methods. According to usage, warp, weft or both yarns can be chosen as conductive yarns, so connection between electronical devices is provided by conductive surface (Figure 7).

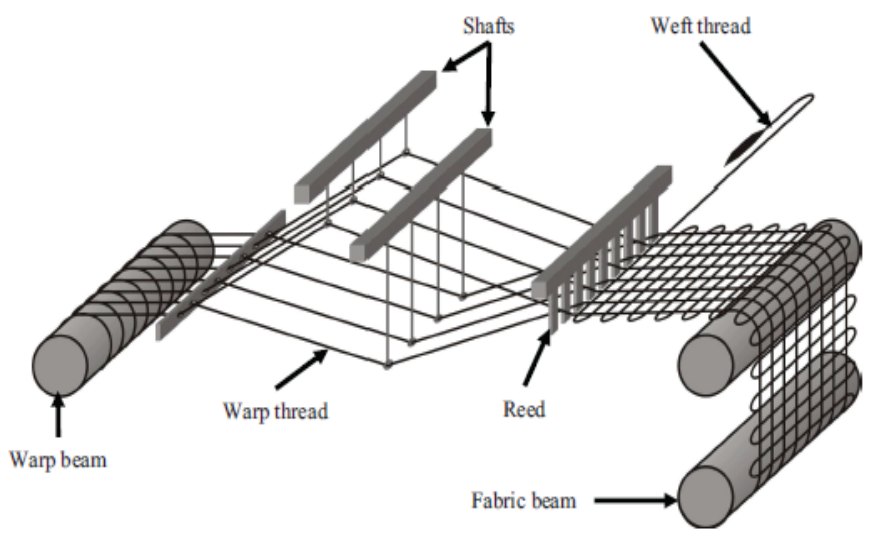

Figure 7. Conductive weaving process [15]

\section{EXPERIMENTAL}

\section{a. Materials}

Conductive yarn specification:

In this study, Ag coated Shieldex ${ }^{\circledR}$ conductive yarn has been used and its technical specifications have been given in Table 1. 
Table 1 . Ag coated Shieldex ${ }^{\circledR}$ conductive yarn specifications

\begin{tabular}{|l|c|}
\hline Description & Silver Plated Nylon 6.6 Yarn 110/34 dtex 2-ply \\
\hline Liner Resistance & $<500 \Omega / \mathrm{m}$ \\
\hline Yield & $36,500 \mathrm{~m} / \mathrm{kg}$ \\
\hline Tenacity & Average $28 \mathrm{cN} / \mathrm{tex}$ \\
\hline Elongation & abt. $15 \%$ \\
\hline Denier & $200 / 68 \mathrm{f}(\mathrm{S} 600550 \mathrm{tpm} \mathrm{Z})$ \\
\hline Melt Point $\left({ }^{\circ} \mathrm{C}\right)$ & 255 \\
\hline
\end{tabular}

Conductive fabric specification:

Two types knitted fabric has been produced by using Ag coated Shieldex ${ }^{\circledR}$ conductive yarn. Specifications of the fabrics are given in Table 2 and Table 3.

Table 2. Specifications of pattern 1 fabric

\begin{tabular}{|l|l|}
\hline Surface Resistance & Average $<5$ Ohms/ \\
\hline Thickness & $0,45 \mathrm{~mm}$ \\
\hline Weight & $140 \mathrm{~g} / \mathrm{m}^{2}$ \\
\hline Fiber & $78 \%$ Nylon $+22 \%$ elastomer \\
\hline Knit type & Supreme \\
\hline The number of loops & 28 loop sequences, 28 wale \\
\hline
\end{tabular}

Table 3. Specifications of pattern 2 fabric

\begin{tabular}{|l|l|}
\hline Surface Resistance & Average $<5 \mathrm{Ohms} /$ \\
\hline Thickness & $0,55 \mathrm{~mm}$ \\
\hline Weight & $224 \mathrm{~g} / \mathrm{m}^{2}$ \\
\hline Fiber & $78 \%$ Nylon $+22 \%$ elastomer \\
\hline Knit type & Raschel warp knitting \\
\hline The number of loops & 15 loop sequences, 21 wale \\
\hline
\end{tabular}

Chemical specifications:

$\mathrm{pH}$ of the perspiration changes for women and men, so two types of perspiration solution have been prepared. Used chemicals are given in Table 4.

Table 4. Used chemicals specifications in TS EN ISO 105-E04 standard

\begin{tabular}{|l|c|}
\hline Chemicals & Amount \\
\hline Distilled water & - \\
\hline Histidine monohydrochloride monohydrate & $0,5 \mathrm{gr}$ \\
\hline $\mathrm{NaCl}$ & $5 \mathrm{gr} / 1$ \\
\hline Disodium hydrogen phosphate & $2,5 \mathrm{gr}$ \\
\hline Sodium hydroxide solution & - \\
\hline
\end{tabular}

\section{b. Methods}

In this study, two types of the knitted fabrics has been produced by using Ag coated Shieldex ${ }^{\circledR}$ conductive yarn. Pattern 1 has been knitted as supreme structure with 28 loop sequences, 28 wale loops and $140 \mathrm{~g} / \mathrm{m}^{2}$ weight. Pattern 2 has been knitted as raschel structure with 15 loop sequences, 21 wale loops and $224 \mathrm{~g} / \mathrm{m}^{2}$ weight. These fabrics are different from each other as loops numbers and weights, so we can determine effect of the perspiration on conductivity in different fabric structure.

Second stage of the study is to prepare the perspiration solutions in terms of woman and man sweat pHs. $10.5 \mathrm{gr}$ Histidine monohydrochloride monohydrate, $5 \mathrm{gr} \mathrm{NaCl}$ and 5 gr disodiumhidrogen Phosphate were solved together in 950 $\mathrm{mL}$ distilled water and $\mathrm{pH}$ were kept in acid 5,5 and alkali 8 by using Sodium Hydroxide solution and Disodium hydrogen phosphate. Solution were completed to $1000 \mathrm{~mL}$.

Third stage of the study is to prepare the patterns, application of them into perspiration solution and measuring the resistance (ohm). TS EN ISO 105-E04 standard has been used in preparing the patterns and these patterns has been cut as $100 \mathrm{~mm}$ x $40 \mathrm{~mm}$ sizes for each sample. Patterns were put into acid and alkali solution as the Figure 8 and these samples were waited for 30 minutes in the room temperature. Measuring the resistances of the patterns were applied in different times as wet condition, 10 minutes later, 30 minutes later and dry condition.
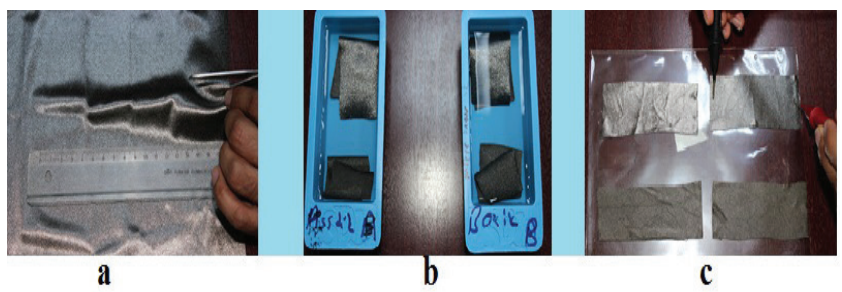

Figure 8. Preparing and measuring of the patterns (a: cutting of the patterns, b: putting the samples into solution, c: measuring the resistance of patterns)

In addition to resistance measuring, SEM photos of these patterns were taken, well by using EVO LS10. Photos of the patterns were taken in four different distances.

\section{RESULTS AND DISCUSSION}

Electricity is affected by many things such as resistance and electricity flows easier if resistance is lower. $\mathrm{pH}$ measurements can be different for woman and man, so 2 type applications in $\mathrm{pH}$ have been made for acid and alkali. According the results, it has been found that conductivity increased for each pattern and $\mathrm{pH}$ solutions because of decreasing resistance. It is seen that there are different results for acid and alkaline patterns because of different fabric types and solution 
$\mathrm{pH}$. As the seen from Figure 9, the lowest conductivity is in original condition in both patterns and perspiration solution makes positive contribution to conductivity. Conductivity has changed negatively when the time has passed because of decreasing solution in the fabric structures.

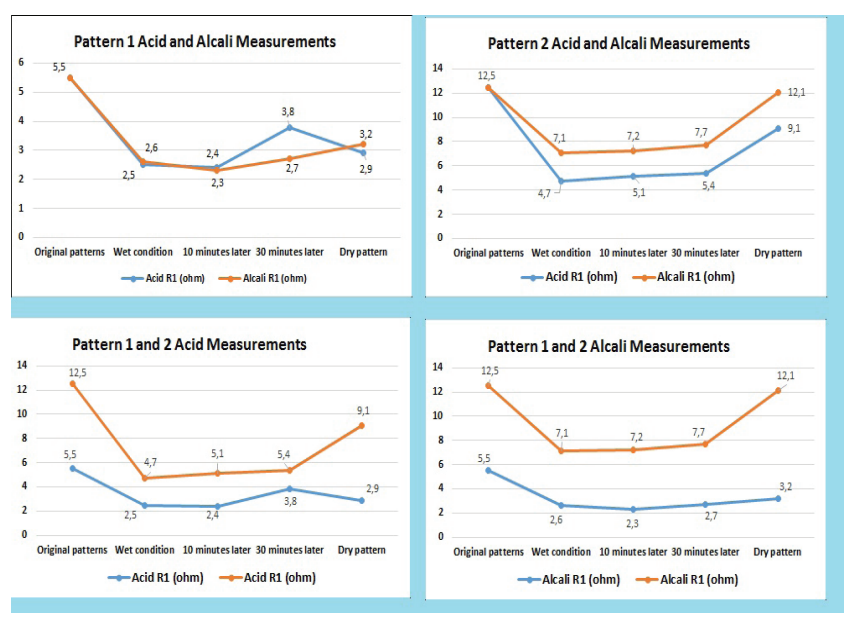

Figure 9. Resistance measurements of the patterns

An interesting result has been seen in dry pattern conductivity because original patterns have lower conductivities. It may occur from the solution chemical, changing fabric structure and environmental conditions.

Table 5. Resistance results of the patterns

\begin{tabular}{|l|c|c|c|c|}
\hline \multirow{2}{*}{} & \multicolumn{2}{|c|}{ Pattern 1 } & \multicolumn{2}{c|}{ Pattern 2 } \\
\cline { 2 - 5 } & Acid & Alkali & Acid & Alkali \\
\cline { 2 - 5 } & R1 (ohm) & R1 (ohm) & R1 (ohm) & R1 (ohm) \\
\hline Original patterns & 5,5 & 5,5 & 12,5 & 12,5 \\
\hline Wet condition & 2,5 & 2,6 & 4,7 & 7,1 \\
\hline 10 minutes later & 2,4 & 2,3 & 5,1 & 7,2 \\
\hline 30 minutes later & 3,8 & 2,7 & 5,4 & 7,7 \\
\hline Dry pattern & 2,9 & 3,2 & 9,1 & 12,1 \\
\hline
\end{tabular}

According to SEM results, all patterns have been affected by perspiration solution and all patterns have some structural degradations. The highest structural degradation has been seen in Pattern 1 for acid, and in Pattern 2 for acid. These degradations can become due to a number of factors such as the fabric structure (fabric weight, fibre, chemical reactions and yarn count etc.), chemical reactions. Acid solutions have affected the fabric structures more but these effects doesn't change the conductivity critically. As seen from Figure 10, pattern 2 alkali and pattern 1 acid have more remains on surfaces, but result have been examined, only pattern 1 acid has been affected by perpiration more. We get from SEM photos that remains can't show parallel results with perspiring. When we consider affect of fabric gramaj, even pattern 2 heavier than pattern 1, change of conductivity has becomes much more in pattern 1 sample. Pattern 2 can protect itself from the affects of perspiring chemical solution because of thicker and heavier structure. Knitting type is a factor in comparision of perspiring affect and results show that rachel samples have affected more than supreme sample because of it's structure with hole. This structure of Rachel sample lets chemical solution penetrate deeply.

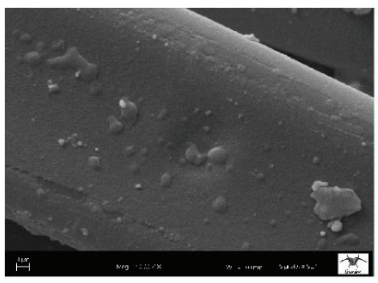

1

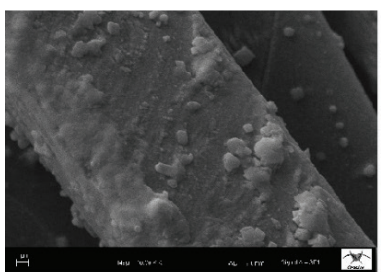

3

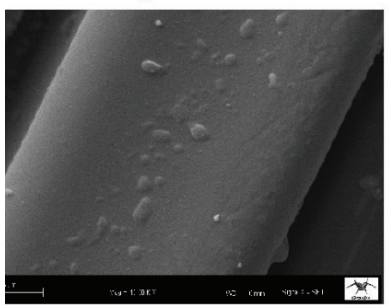

5

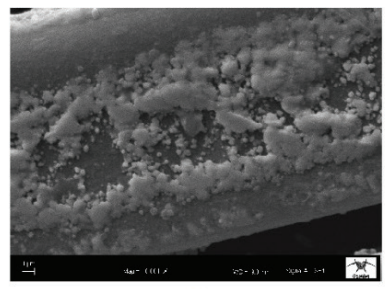

2

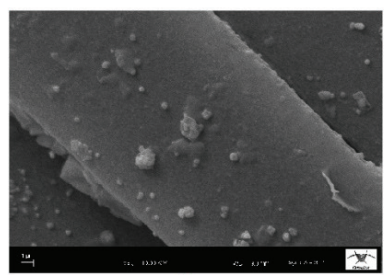

4

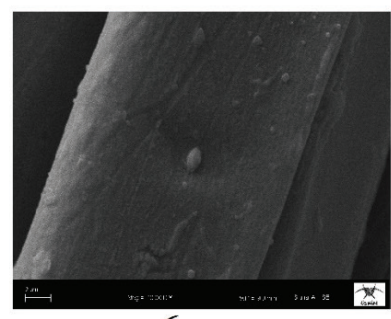

6
Figure 10. SEM photos of patterns (1: pattern 2 acidic; 2: pattern 2 alkaline; 3: pattern 1 acidic; 4: pattern 1 alkaline; 5: neutral pattern $2 ; 6$ : neutral pattern 1 )

Conductivity changes with solution and this changes makes positive contribution to conductivity by decreasing resistance at first stage of the application, time after time conductivity decreases but it doesn't become the original conductivity.

\section{CONCLUSION}

In this study, 2 types knitted fabric were knitted by using Ag coated Shieldex ${ }^{\circledR}$ conductive yarn, and then perspiration solution were prepared in accordance with TS EN ISO 105-E04 standard and this solution were applied on 
knitted conductive patterns as acid and alkali. Results of patterns have been examined and commented. It is found that perspiration doesn't affect the conductivity on conductive textile surface badly. In contrast, conductivity has the better result when perspiration solution used. Fabric weight affects conductivity with perspiring and heavier fabrics can be affected less. One of factors in perspiring affect on conductivity is knitting type. Knitting type is a factor affected by it's surface features and especially fabric type with hole on surface lets the chemicals affect more.

Degredations of fabric can be resulted from many factors, so the other factors in fabric degradations have been examined. It is important that not only do electronic textile circuits have conductive yarn but also they contain other circuits such as sensors, batteries, etc. so in this study we have examined affect of perspiration on only conductive yarn and fabric. The following studies should be about the affect of perspiration on the other circuit materials.

Electronic textiles have big potentials in sector because of it's fascinating and usable ways. More and more new electronic textile designs surface in sector but there is a need on their working performance for long times, so it is though that such studies will make contribution on this way.

\section{References}

[1] Fishlock, D. (2001). Doctor volts. IEE Review, 5, 23-28.

[2] Bilir M. Z. and Gürcüm B. H.. (2015). A Piezo-resistive Application in Textile Design. Marmara Journal of Pure and Applied Sciences, 58-60.

[3] Wearable Computing, http://www.engadget.com/2013/09/18/ edward-thorp-father-of-wearable-computing/, (January 2016).
[4] Park S. and Jayaraman S. (1999). Adaptive and responsive textile structures, Journal of Virtual Reality , 4, 152-168.

[5] Zieba J. and Frydrysiak M. (2006). Textronics - Electrical and Electronic Textiles Sensors for Breathing Frequency Measurement. Fibres \& Textiles In Eastern Europe, 14, 4348.

[6] Şenel F. (2010). Terleme. Bilim ve Teknik, 98-99.

[7] Sweet Glands, http://health.howstuffworks.com/wellness/ men/sweating-odor/understanding-eccrine-sweat-glands 1. htm, (January 2016).

[8] Demir A., Öktem T. and Seventekin N. (2008). The Effect Of Uv Absorbers On Light Fastness Of Reactive Dyed Cotton Fabrics. Tekstil ve Konfeksiyon, 211-220.

[9] Bauer C., Jacques P. and Kalt A. (2001). Photooxidation of an azo dye induced by visible light incident on the surface of $\mathrm{TiO}_{2}$. Journal of Photochemistry and Photobiology A: Chemistry, 87-92.

[10] Guo L., Wiklund U. and Mattila H. (2013). Design of a garment-based sensing system for breathing monitoring. Textile Research Journal, 5, 499-509.

[11] Curone D., Secco E. L., Tognetti A., Loriga G., Dudnik G., Risatti M., Whyte R., Bonfiglio A. and Magenes G. (2010). Smart Garments for Emergency Operators: The ProeTEX Project. Ieee Transactions On Information Technology In Biomedicine, 14.

[12] Media Mit, http://web.media.mit.edu/ leah/grad_work/diy/ diy_tank.html, (Januarry 2016).

[13] Bedeloğlu A., Sünter N. and Bozkurt Y. (2010). Electrically conductive textiles, production methods and usage areas. The Journal Of Textiles and Engineers, 79, 7-17.

[14] Media Mit, http://web.media.mit.edu/ leah/grad_work/diy/ diy_tank.html, (January 2016).

[15] Zysset C., Kinkeldei T. W., Münzenrieder R., Cherenack K. and Tröster G. (2012). Integration Method for Electronics in Woven Textiles. Ieee Transactions On Components, Packaging And Manufacturing Technology, 2, 1107-1117. 